\title{
Self-Efficacy dan Kepuasan Kerja pada Guru Taman Kanak-Kanak (TK)
}

\author{
Nur Hasanah ${ }^{1}$, Nadhirotul Laily² \\ nurhasanah1345@gmail.com¹, nadhirotul.laily@umg.ac.id² \\ Fakultas Psikologi, Universitas Muhammadiyah Gresik ${ }^{1,2}$
}

\begin{abstract}
The purpose of this research is to find out the relathionship between self-efficacy and job satisfaction teacher at Preschool. This research is quantitative using correlation technique. The population is the teachers at Preschool 'Aisyiyah Bustanul Athfal Gresik. Incidental sampling was used and 98 teachers have been selected as sample. The instrument was used by the reseachers were self-efficacy and job satisfaction scale. The correlation test result shows $r=0,127, p=0,213(p>0,05)$. Based on correlation test result, it can be consluded that $\mathrm{Ha}$ rejected and $\mathrm{HO}$ accepted. There is no positive relationship between self-efficacy and job satisfaction teacher at Preschool.
\end{abstract}

Keywords: self-efficacy, job satisfaction, teachers.

\begin{abstract}
Abstrak
Tujuan dari penelitian ini adalah untuk menjelaskan hubungan antara self-efficacy dengan kepuasan kerja pada guru Taman Kanak-Kanak (TK). Penelitian ini bersifat kuantitatif korelasional. Populasi dalam penelitian ini adalah guru TK 'Aisyiyah Bustanul Athfal di Kabupaten Gresik yang menggunakan insidental sampling, dengan jumlah sampel 98 guru. Instrumen yang digunakan adalah skala selfefficacy dan skala kepuasan kerja. Hasil uji korelasi menunjukkan $r=0,127, p=0,213(p>0,05)$. Berdasarkan hasil uji korelasi ditarik kesimpulan Ha ditolak dan $\mathrm{H}_{0}$ diterima. Hal ini menunjukkan tidak ada hubungan signifikan antara self-efficacy dengan kepuasan kerja pada guru Taman Kanak-Kanak (TK).
\end{abstract}

Kata Kunci: self-efficacy, kepuasan kerja, guru.

\section{PENDAHULUAN}

Pendidikan merupakan dasar utama untuk memajukan serta meningkatkan martabat dan kemajuan peradaban suatu bangsa. Proses pendidikan dapat berjalan dengan maksimal jika semua unsur pendidikan dapat bekerja sama dengan baik. Unsur-unsur pendidikan antara lain yaitu anak didik, guru, proses pembelajaran, tujuan pembelajaran, materi pembelajaran, alat dan metode pembelajaran serta lingkungan tempat pembelajaran berlangsung (Tirtarahardja \& Sulo, 2012:51-52).

Menurut Sardiman (2014:125) salah satu unsur penting dalam tahapan pembelajaran adalah guru, karena guru memiliki peran dalam pembentukan potensi sumber daya manusia. Dibidang pendidikan, guru merupakan tenaga profesional yang harus mampu berperan aktif dan mengarahkan serta membimbing siswanya agar menjadi individu yang baik sesuai dengan standar masyarakat yang semakin dinamis.

Guru memiliki peran penting dalam melaksanakan tujuan pendidikan khususnya untuk mengembangkan sikap positif terhadap tanggungjawab pekerjaan dan menghindari sikap negatif, sebab hal tersebut dapat berpengaruh terhadap pekerjaannya. Tugas utama seorang guru adalah membimbing siswa, maka guru harus mampu mengawasi dan membina siswanya. Untuk itu kadar kualitas guru merupakan penentu tinggi rendahnya keyakinan guru di suatu sekolah (Cahyono, 2015:31). Dengan demikian tugas dan tanggungjawab guru dalam 


\section{Efektor, Volume 7 Issue 1, 2020, Pages 80 - 89 \\ Nur Hasanah, Nadhirotul Laily}

proses pelaksanaan dan pencapaian tujuan pendidikan merupakan suatu hal sangat penting sehingga dibutuhkan dukungan dari berbagai pihak.

Taman Kanak-Kanak (TK) adalah salah satu tingkat pendidikan formal pertama setelah pendidikan keluarga (di rumah) dan merupakan mediasi antara rumah (keluarga) dengan masyarakat yang lebih umum. Berdasarkan Keputusan Mendiknas RI Nomor 0487 Tahun 1992 Bab 1 pasal 2 dinyatakan bahwa Taman KanakKanak merupakan sarana untuk membantu pertumbuhan dan perkembangan jasmani dan rohani anak didik yang berusia 4-6 tahun dengan lama Pendidikan 1-2 tahun (Hartawati \& Mariyati, 2014:54).

Pada pendidikan anak usia 4-6 tahun dibutuhkan pengajar yang memiliki kompetensi yang baik agar pendidikan anak terjamin. Namun sayangnya, kesejahteraan guru Taman Kanak-Kanak kurang diperhatikan dibandingkan dengan guru pada tingkat atau jenjang pendidikan yang lebih tinggi. Padahal guru TK bertugas mendidik anak pada usia emas dimana pada usia ini perkembangan kecerdasan mengalami peningkatan yang pesat.

Berdasarkan data Badan Pusat Statistik (BPS) jumlah guru TK di Provinsi Jawa Timur pada tahun 20112014 terjadi peningkatan dari 43.634 guru pada tahun 2011/2012 bertambah menjadi 44.144 pada tahun 2012 2013 dan pada tahun 2013 - 2014 bertambah menjadi 63.348 orang. Sedangkan pada tahun 2014 - 2015 mengalami penurunan menjadi 59.729 guru (https://www.bps.go.id/statictable/2015/09/10/1809/jumlah-sekolahguru-dan-murid-taman-kanak-kanak-tk-di-bawah-kementrian-pendidikan-dan-kebudayaan-menurut-provinsitahun-ajaran-2011-2012-2015-2016.html, diakses pada tanggal 14 November 2017).

Keyakinan diri (self-efficacy) adalah hal yang sangat berpengaruh terhadap guru dalam melaksanakan pekerjaannya. Self-efficacy adalah karakteristik bagi guru yang sangat penting untuk meningkatkan kemampuan keyakinan diri dalam melaksanakan seluruh tanggungjawabnya, sehingga aktivitas di sekolah atau Taman KanakKanak (TK) dapat terlaksana dengan baik dan dengan demikian guru juga mengalami peningkatan kepuasan dalam bekerja (Dewi \& Dewi, 2015:16).

Bloom dan Naylor (1968) dalam Rahman (2013:4) mendefinisikan kepuasan kerja sebagai hasil dari beberapa sikap yang dimiliki oleh seorang pegawai terhadap pekerjaannya. Hal ini merujuk pada seberapa besar individu lebih menyukai bekerja, sehingga ketika yang bersangkutan mampu konsisten dengan pekerjaannya yaitu Ketika ia mampu memenuhi standar kerja dan seberapa besar ia bangga dengan realita terhadap perkembangan individu dan institusi tempat ia bekerja.

Kepuasan kerja pada dasarnya adalah sesuatu yang bersifat pribadi, tiap pribadi mempunyai level kepuasan yang tidak sama sesuai dengan mekanisme yang berlaku pada dirinya. Semakin tinggi penilaian terhadap aktivitas yang dirasakan sesuai dengan keinginan individu, maka semakin tinggi kepuasannya terhadap aktivitas tersebut. Dengan demikian, kepuasan adalah evaluasi yang mendeskripsikan seseorang atas perasaan senang atau tidak senang, puas tidak puas dalam bekerja. Howell dan Dipboye (1986 dalam Munandar, 2014:350) 


\section{Efektor, Volume 7 Issue 1, 2020, Pages 80 - 89 \\ Nur Hasanah, Nadhirotul Laily}

melihat kepuasan kerja sebagai output yang menyeluruh dari tingkat rasa suka atau tidak sukanya tenaga kerja terhadap berbagai aspek dari beban tugasnya.

Keyakinan akan self-efficacy sangat diperlukan oleh seorang guru TK karena mampu mempengaruhinya dalam menuntaskan berbagai persoalan yang berhubungan dengan bidang akademik. Guru dengan self-efficacy yang tinggi mampu mengelola stres akademik dengan mengarahkan mereka pada usaha penyelesaian masalah, sebaliknya guru yang memiliki self-efficacy rendah akan mencoba untuk menghindari berurusan dengan masalah akademis (Bandura, 1997). Dengan demikian guru yang memiliki self-efficacy yang tinggi akan mengerahkan usaha yang tinggi ketika menghadapi kesulitan untuk menjalani tuntutan tugasnya sebagai pengajar.

\section{Self-Efficacy}

Bandura (1997) mengatakan bahwa self-sefficacy merupakan keyakinan individu dalam melaksanakan tugas atau tindakan yang dibutuhkan untuk mencapai target tertentu. Sedangkan Baron dan Byrne mengemukakan bahwa self-efficacy merupakan penilaian seseorang tentang kemampuan atau kompetensi dirinya untuk melaksanakan suatu tugas, mencapai target, dan mengatasi kendala (Ghufron \& Risnawita, 2014:73-74). Selfefficacy pada dasarnya adalah hasil dari proses kognitif berupa keputusan, keyakinan, atau pengharapan tentang sejauh mana individu menilai dan memperkirakan kemampuannya dalam melaksanakan tugas atau tindakan tertentu yang diperlukan agar mendapatkan hasil yang diinginkan.

\section{Dimensi Self-Efficacy}

Menurut Bandura (1997 dalam Ghufron \& Risnawita, 2014:80) self-efficacy yang dimiliki individu tidak akan sama antar satu individu dengan yang lainnya berdasarkan 3 dimensi. Dimensi tersebut antara lain:

1. Dimensi Tingkat (Level)

Berhubungan dengan tingkat kesulitan tugas yang dihadapi. Keyakinan dan penerimaan individu terhadap suatu tugas tidak sama, mungkin orang hanya terbatas pada tugas yang sederhana, menengah atau sulit. Persepsi setiap individu akan berbeda dalam memandang suatu tingkat kesulitan dari suatu tugas (Suharsono \& Istiqomah, 2014:146).

2. Dimensi Generalisasi (Generality)

Adalah perasaan kemampuan yang ditunjukkan individu pada situasi tugas yang berbeda-beda, baik itu melalui perilaku, pikiran, maupun sikapnya (Suharsono \& Istiqomah, 2014:146).

3. Dimensi Kekuatan (Strength)

Merupakan kuatnya keyakinan seseorang terhadap kemampuan yang dimiliki. Hal tersebut berhubungan dengan daya tahan dan keuletan individu dalam pemenuhan tanggungjawabnya. Individu yang memiliki keyakinan serta kemantapan yang kuat terhadap kemampuannya untuk mengerjakan suatu tugas akan terus bertahan dalam usahanya meskipun banyak mengalami hambatan dan tantangan. Pengalaman memiliki pengaruh terhadap self-efficacy yang diyakini seseorang. Pengalaman yang lemah akan melemahkan 


\section{Efektor, Volume 7 Issue 1, 2020, Pages 80 - 89}

Nur Hasanah, Nadhirotul Laily

keyakinan individu itu juga. Individu yang memiliki keyakinan yang kuat terhadap kemampuan mereka akan teguh dalam usaha untuk menyampaikan kesulitan yang dihadapi (Suharsono \& Istiqomah, 2014:146).

\section{Kepuasan Kerja}

Kepuasan kerja (job satisfaction) merupakan kondisi emosi yang menyenangkan atau tidak menyenangkan yang dirasakan oleh para pegawai terhadap tugasnya. Kepuasan kerja merefleksikan perasaan individu terhadap pekerjaannya yang nampak dalam sikap positif pegawai terhadap pekerjaan dan semua hal yang dihadapi di lingkungan tempat ia bekerja (Handoko, 2014:193). Howell dan Dipboye (1986 dalam Munandar, 2014:350) melihat kepuasan kerja sebagai hasil keseluruhan dari tingkat rasa suka atau tidak sukanya pegawai terhadap berbagai aspek dari pekerjaannya.

Spector (1997:2) mengartikan kepuasan kerja sebagai sikap yang merefleksikan perasaan individu terhadap pekerjaanya baik secara keseluruhan ataupun tiap-tiap aspek pekerjaannya. Perasaan tersebut dapat berupa kesukaan ataupun ketidaksukaan terhadap pekerjaannya.

\section{Aspek Kepuasan Kerja}

Spector (1997:8) mendefinisikan kepuasan kerja sebagai sikap yang mencerminkan perasaan seseorang tentang pekerjaan mereka, baik secara menyeluruh maupun tiap bagian pekerjaannya. Spector (1997:8) mengidentifikasikan kepuasan kerja dari sembilan (9) aspek yaitu :
1. Pay
: nominal upah dan rasa keadilannya
2. Promotion
: kemungkinan dan rasa keadilan untuk mendapatkan promosi
3. Supervision
: keadilan dan kompetensi penugasan menajerial oleh supervisor
4. Benefit
: asuransi, liburan dan bentuk fasilitas yang lain
5. Contingent rewards
: rasa hormat, diakui dan diberikan penghargaan
6. Operating procedures
: kebijakan, prosedur dan aturan
7. Coworkers
: rekan kerja yang menyenangkan dan kompeten
8. Nature of work
: tugas itu sendiri dapat dinikmati atau tidak
9. Communication
: berbagai informasi didalam organisasi (verbal maupun nonverbal)

\section{Kerangka Konseptual}

Kerangka konseptual dalam penelitian ini adalah :

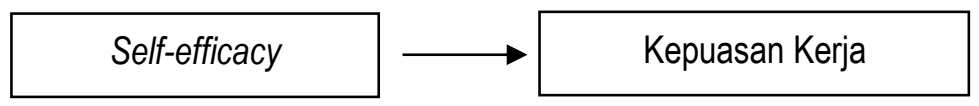

Gambar 1. Kerangka Konseptual

\section{Hipotesis Penelitian}

$\mathrm{Ha}$ : Ada hubungan antara self-efficacy dengan kepuasan kerja pada guru Taman Kanak-Kanak (TK).

Ho : Tidak ada hubungan antara self-efficacy dengan kepuasan kerja pada guru Taman Kanak-Kanak (TK). 


\section{Efektor, Volume 7 Issue 1, 2020, Pages 80 - 89}

Nur Hasanah, Nadhirotul Laily

\section{METODE PENELITIAN}

Penelitian ini adalah jenis riset kuantitatif deskriptif. Tipe riset yang digunakan adalah penelitian korelasi yang bertujuan untuk menjelaskan hubungan antara self-efficacy dengan kepuasan kerja pada guru Taman KanakKanak (TK), Azwar (2014:8).

Populasi dalam penelitian ini adalah guru TK 'Aisyiyah Bustanul Athfal (ABA) di Kabupaten Gresik. Teknik pengambilan sampel yang digunakan adalah teknik Nonprobability Sampling dengan Sampling Insidental. Sampel dalam penelitian ini berjumlah 98 guru TK.

Kuesioner dan hasil wawancara merupakan teknik pengumpulan data dalam penelitian ini. Penelitian ini menggunakan skala self-efficacy yang disusun oleh James dan Maddux (1995) dan telah diadaptasi kedalam Bahasa Indonesia oleh Suharsono dan Istiqomah (2014). Sedangkan indikator kepuasan kerja dari Spector (1997:8) digunakan peneliti untuk menyusun skala kepuasan kerja.

\section{Uji Validitas}

Uji validitas dalam riset ini menggunakan validitas isi, yaitu validitas yang diestimasi dengan menggunakan pengujian terhadap isi tes dengan analisis rasional atau melalui profesional judgement. Syarat minimum adalah apabila $r=0,3$. Sehingga apabila korelasi antara butir dengan skor total kurang dari 0,3 maka butir tersebut dinyatakan tidak valid (Sugiyono, 2016:187-188).

\begin{tabular}{|c|c|c|c|c|}
\hline \multirow[t]{2}{*}{ No } & \multirow[t]{2}{*}{ Aspek } & \multicolumn{2}{|c|}{ Item } & \multirow[t]{2}{*}{ Jumlah } \\
\hline & & Favourable & Unfavavourable & \\
\hline 1 & Level & - & $5,6,10,13,15,17,20$ & 7 \\
\hline 2 & Generality & 18 & $2,7,9,11,16,19$ & 7 \\
\hline 3 & Strenght & $1^{*}, 3^{*}, 8^{*}, 12^{*}, 14,21$ & 4 & 7 \\
\hline & Total & 7 & 14 & 21 \\
\hline
\end{tabular}

Berdasarkan tabel 1 diatas terdapat 17 item yang sahih dari 21 item pada variabel self-efficacy. Item dianggap sahih karena memenuhi koefisien korelasi minimal 0,30. Item sahih ditunjukkan dari nilai $r$ yang berkisar 0,3-0,5. Sedangkan, 4 item yang dianggap gugur karena memiliki nilai koefisien korelasi kurang dari 0,30

Tabel 2. Hasil Uji Validitas Skala Kepuasan Kerja

\begin{tabular}{lllccc}
\hline No & \multicolumn{1}{c}{ Aspek } & \multicolumn{1}{c}{ Indikator } & Favourable & Unfavavourable & Total \\
\hline 1 & Gaji & $\begin{array}{l}\text { Merasa puas akan keadilan gaji yang } \\
\text { diterima }\end{array}$ & 1,11 & $22,29,34$ & 5 \\
2 & Promosi & $\begin{array}{l}\text { Merasa puas akan adanya kesempatan } \\
\text { promosi yang adil }\end{array}$ & $2,10^{*}$ & $26,37^{*}$ & 4 \\
3 & Supervisi & $\begin{array}{l}\text { Merasa puas akan kompetensi atasan } \\
\text { a. Merasa puas dengan tunjangan yang }\end{array}$ & 3,13 & $17^{*}, 21$ & 4 \\
& Tunjangan & $\begin{array}{l}\text { diberikan Sekolah } \\
\end{array}$ & & 35 & 2
\end{tabular}


Efektor, Volume 7 Issue 1, 2020, Pages 80 - 89

Nur Hasanah, Nadhirotul Laily

\begin{tabular}{|c|c|c|c|c|c|}
\hline & & b. Merasa puas akan fasilitas yang & 12 & 31 & 2 \\
\hline \multirow[t]{2}{*}{5} & Penghargaan & $\begin{array}{l}\text { a. Merasa senang akan apresiasi kerja } \\
\text { yang diakui }\end{array}$ & 5 & 23,28 & 3 \\
\hline & & $\begin{array}{l}\text { b. Merasa senang dengan rasa hormat } \\
\text { yang diterima dari lingkungan }\end{array}$ & 15 & 30 & 2 \\
\hline \multirow[t]{2}{*}{6} & Prosedur & a. Merasa puas akan prosedur sekolah & 6 & 19 & 2 \\
\hline & & $\begin{array}{l}\text { b. Merasa puas dengan kebijakan yang } \\
\text { diterapkan sekolah }\end{array}$ & 16,41 & 38 & 3 \\
\hline \multirow[t]{2}{*}{7} & Rekan Kerja & $\begin{array}{l}\text { a. Merasa puas akan interaksi dengan } \\
\text { rekan kerja }\end{array}$ & 7,39 & $24,27,32$ & 5 \\
\hline & & $\begin{array}{l}\text { b. Merasa puas akan kompetensi yang } \\
\text { dimiliki rekan kerja }\end{array}$ & 14 & 20 & 2 \\
\hline 8 & Sifat Kerja & $\begin{array}{l}\text { Merasa puas atas kesesuaian pekerjaan } \\
\text { yang dilakukan }\end{array}$ & 8,36 & $18,25,33$ & 5 \\
\hline \multirow[t]{2}{*}{9} & Komunikasi & $\begin{array}{l}\text { Merasa puas akan komunikasi dengan } \\
\text { warga sekolah }\end{array}$ & 9 & 40 & 2 \\
\hline & & Total & 19 & 22 & 41 \\
\hline
\end{tabular}

Keterangan :Tanda (*) Menunjukkan item tidak valid

Berdasarkan hasil dari tabel 2, dari total 41 item pada variabel kepuasan kerja terdapat 3 item yang gugur sehingga total item yang sahih berjumlah 38. Item dianggap sahih karena memenuhi koefisien korelasi minimal 0,30 . Item sahih ditunjukkan dari nilai $r$ yang berkisar $0,3-0,7$. Sedangkan, 3 item yang dianggap gugur karena memiliki nilai koefisien korelasi kurang dari 0,30.

Berdasarkan perhitungan validitas item pada variabel self-efficacy dan kepuasan kerja yang telah dilakukan, maka item yang gugur tidak dipergunakan. Sedangkan item yang sahih pada perhitungan validitas terhadap variabel self-efficacy dan kepuasan kerja dapat langsung dipergunakan untuk analisis data penelitian.

\section{Uji Reliabilitas}

Suatu skala dapat dikatakan reliabel apabila nilai koefisien reliabilitas (rxy) >0,60 (Sujarweni, 2014:85). Pengujian reliabilitas dalam riset ini menggunakan teknik statistik melalui koefisien Alpha Cronbach dengan Reliability Analysis. Perhitungan tersebut dapat diperoleh melalui penyajian suatu skala hanya sekali saja pada sekelompok responden (Single Trial Administration) (Azwar, 2015: 98).

Tabel 3. Uji Reliabilitas Skala

\begin{tabular}{lccc}
\hline Variabel & Nilai Alpha Cronbach & Cut of value & Kesimpulan \\
\hline Self-efiicacy & 0,746 & 0,60 & Reliabel \\
Kepuasan kerja & 0,928 & 0,60 & Reliabel \\
\hline
\end{tabular}

Hasil dari tabel 3 menjelaskan bahwa nilai reliabilitas (Alpha Cronbach) tiap variabel. Dapat disimpulkan bahwa semua variabel dalam penelitian ini adalah reliabel karena nilai kedua variabel tersebut di atas 0,60 , dengan rincian variabel self-efficacy memiliki nilai reliabilitas sebesar 0,746 dan variabel kepuasan kerja memiliki nilai reliabilitas sebesar 0,928 . 


\section{Efektor, Volume 7 Issue 1, 2020, Pages 80 - 89}

Nur Hasanah, Nadhirotul Laily

\section{Uji Normalitas}

Hasil uji normalitas data menggunakan Kolmogorof-Smirnof Test dengan bantuan SPSS 16 for widows. Diperoleh angka probabilitas self-efficacy sebesar 0,014, sedangkan kepuasan kerja sebesar 0,000. Nilai probabilitas tersebut lebih kecil dari 0,05 maka bisa disimpulkan bahwa data penelitian tidak berdistribusi normal.

\section{HASIL DAN PEMBAHASAN}

Analisis data dalam penelitian ini menggunakan statistik non parametrik karena berdasarkan uji normalitas ditemukan bahwa data penelitian ini tidak berdistribusi normal. Dalam menganalisis data dalam penelitian ini adalah dengan menggunakan bantuan SPSS ver. 16 for windows.

\section{Uji Korelasi}

Tabel 4. Hasil Uji Korelasi

\begin{tabular}{|c|c|c|c|c|}
\hline \multicolumn{5}{|c|}{ Correlations } \\
\hline & & & Self_Efficacy & Kepuasan_kerja \\
\hline \multirow{6}{*}{$\begin{array}{l}\text { Spearman's } \\
\text { rho }\end{array}$} & Self_Efficacy & Correlation Coefficient & 1.000 & .127 \\
\hline & & Sig. (2-tailed) & . & .213 \\
\hline & & $\mathrm{N}$ & 98 & 98 \\
\hline & Kepuasan_kerja & Correlation Coefficient & .127 & 1.000 \\
\hline & & Sig. (2-tailed) & .213 & . \\
\hline & & $\mathrm{N}$ & 98 & 98 \\
\hline
\end{tabular}

Jika nilai probabilitas >0,05 (atau 0,01), maka $\mathrm{H}_{0}$ diterima (Sutanto, 2005:75). Hasil analisis data korelasi Spearman Rank menunjukkan angka $r=0,127, p=0,213$ tidak ada sig (2-tailed) yang artinya korelasinya tidak signifikan karena lebih besar dari 0,05 $(p>0,05)$. Sehingga hipotesis nol $\left(\mathrm{H}_{0}\right)$ diterima dan hipotesis alternatif $(\mathrm{Ha})$ ditolak yang artinya tidak ada hubungan positif yang signifikan antara self-efficacy dengan kepuasan kerja pada guru Taman Kanak-Kanak(TK).

Berdasarkan tabel 4 di atas $r$ hitung $=0,127$ maka koefisien $\left(r^{2}\right)=0,0161$ (berarti 1,61\%). Hal tersebut menginformasikan bahwa kontribusi variabel self-efficacy dengan kepuasan kerja pada guru Taman Kanak-Kanak (TK) sebesar 1,61\%. Sedangkan sisanya $98,39 \%$ dipengaruhi oleh variabel lain

Dari hasil uji analisis data diperoleh koefisien korelasi pada variabel self-efficacy dengan kepuasan kerja menghasilkan $r=0,127$ dan $p=0,213>0,05$, sehingga dalam uji hipotesa dapat dinyatakan bahwa tidak ada hubungan antara self-efficacy dengan kepuasan kerja pada guru TK.

Hasil penelitian ini sejalan dengan penelitian Kilapong (2013) di PT. Tropica Cocoprima Manado. Penelitian tersebut menunjukkan bahwa pada karyawan perusahaan tersebut self-efficacy tidak mempengaruhi terhadap kepuasan kerja. Self-efficacy pada pegawai belum tercipta secara menyeluruh, sehingga tidak berpengaruh terhadap kepuasan kerja. 


\section{Efektor, Volume 7 Issue 1, 2020, Pages 80 - 89 \\ Nur Hasanah, Nadhirotul Laily}

Variabel lain yang belum diteliti sebesar $98,86 \%$, kemungkinan dipengaruhi oleh faktor lain yang belum dibatasi oleh peneliti. Hal ini sesuai dengan pendapat Alsaraireh, Griffin, Ziehm \& Fitzpatrick (2014:461) yang mengatakan bahwa faktor-faktor yang mungkin mempengaruhi kepuasan kerja dapat dibagi menjadi karakteristik pribadi (usia, jenis, kelamin, status perkawinan dan pengalaman) dan faktor organisasi. Gilmer: 1966 (dalam Waluyo, 2013:126) menyatakan bahwa aspek-aspek yang mempengaruhi kepuasan kerja yaitu, kesempatan untuk berkembang, keamanan kerja, upah, perusahaan dan manajemen, supervisi, faktor intrinsik dari pekerjaan, kondisi kerja, aspek sosial dalam pekerjaan, komunikasi dan fasilitas.

Hal senada juga disampaikan Tiffin (1958 dalam Anoraga, 2009:82) bahwa kepuasan kerja berkaitan dengan sikap pegawai terhadap pekerjaan itu sendiri, situasi kerja, kerja sama antara atasan dan sesama pegawai. Disebutkan bahwa kepuasan kerja adalah hal yang bersifat pribadi. Semakin banyak faktor-faktor dalam pekerjaan yang sesuai dengan keinginan individu tersebut, maka semakin tinggi tingkat kepuasan yang dirasakannya.

Hasil wawancara terhadap subjek I menjelaskan merasakan puas sebab ia ingin bekerja sesuai dengan tingkat pendidikan yang ditempuh. Selain itu subjek belum menikah, menjadikan pekerjaannya sebagai guru TK untuk bekal dan latihan kelak menjadi seorang ibu dengan belajar bersama anak didiknya. Hasil wawancara tersebut sesuai dengan yang dikemukakan oleh Mulin (1993 dalam Wijono, 2015:128) bahwa faktor individual atau pribadi mempengaruhi kepuasan kerja. Faktor pribadi yang dimaksud Mulin di antaranya kepribadian, pendidikan, inteligensi serta kemampuan, usia, status perkawinan dan orientasi kerja.

Sedangkan dari hasil wawancara terhadap subjek II mengatakan bahwa kepuasan kerja akan didapatkan ketika ia merasa ikhlas dengan apa yang dikerjakannya. Apabila menjalankan segala sesuatu dengan keikhlasan maka akan mendatangkan berkah dalam bekerja. Hal tersebut sesuai dengan pendapat yang dinyatakan oleh Mulin (1993 dalam Wijono, 2015:128) bahwa salah satu faktor yang mempengaruhi kepuasan kerja adalah faktor budaya. Dalam hal ini faktor budaya meliputi sikap-sikap yang melandasi seperti keyakinan dan nilai-nilai yang dianut. Populasi dalam penelitian ini adalah para guru TK 'Aisyiyah Bustanul Athfal dibawah naungan persyarikatan Muhammadiyah yang merupakan salah satu organisasi agama Islam, yang memprioritaskan nilai ikhlas dan ikhsan dalam bekerja.

\section{SIMPULAN}

Berdasarkan analisis data riset, maka dapat disimpulkan bahwa Hubungan antara self-efficacy dengan tingkat kepuasan kerja tidak ada korelasi yang signifikan, dengan nilai signifikansi $p=0,213$ artinya nilai $p>0,05$ sehingga $\mathrm{Ha}$ (Hipotesis Alternatif) ditolak sedangkan $\mathrm{H}_{0}$ (Hipotesis nol) diterima. Hal tersebut memiliki arti bahwa semakin tinggi tingkat self-efficacy, maka belum tentu diikuti oleh tingkat kepuasan kerja. Begitu pula sebaliknya, semakin rendah tingkat self-efficacy maka belum tentu tingkat kepuasan kerja juga rendah. Lebih lanjut Hubungan antara self-efficacy dengan tingkat kepuasan kerja pada guru Taman Kanak-Kanak (TK) sebesar 1,61\%. Selebihnya 98,39\% dipengaruhi oleh variabel lain yang belumdi lakukan penelitian. 


\section{Efektor, Volume 7 Issue 1, 2020, Pages 80 - 89}

Nur Hasanah, Nadhirotul Laily

\section{DAFTAR RUJUKAN}

Alsaraireh, F., Griffin, M.T.Q., Ziehm, S.R., Fitzpatrick, J.J (2014). Job satisfaction and turnover intention among Jordanian nurses in psychiatric units. International Journal of Mental Health Nursing, 23, 460-467. DOI: 10.1111/inm. 12070

Anoraga, P. (2009). Psikologi Kerja. Jakarta : PT Asdi Mahasatya.

Azwar, S. (2014). Metode Penelitian. Yogyakarta: Pustaka Pelajar (2015). Reliabilitas Dan Validitas. Yogyakarta : Pustaka Belajar.

Badan Pusat Statistik. Data Jumlah Guru Di Indonesia. https://www.bps.go.id/statictable/2015/09/10/1809/jumlahsekolah-guru-dan-murid-taman-kanak-kanak-tk-di-bawah-kementrian-pendidikan-dan-kebudayaanmenurut-provinsi-tahun-ajaran-2011-2012-2015-2016.html, diakses pada tanggal 14 November 2017.

Bandura, A. (1997). Self Efficacy The Exercise Of Control. New York: W.H Freeman and Company.

Cahyono, M. Y. (2015). Teacher Self-Efficacy dan Komitmen Organisasi pada Guru TK dan SD di Sekolah Plus Kota Bandung. Humanitas, 2 (1), 46.(Online),(http://majour.maranatha.edu/index.php/hmn/article/view/1704), diakses 2 November 2017.

Dewi, P. E., \& Dewi, I. G. (2015). Pengaruh Self Efficacy Dan Motivasi Kerja Pada Kepuasan Kerja Karyawan Happy Bali Tour \& Travel Denpasar. Jurnal Manajemen, Strategi Bisnis dan Kewirausahaan, 9 (1), 15-25. (Online),(https://ojs.unud.ac.id/index.php/jmbk/article/download/14396/9894/), diakses 10 November 2017

Ghufron, M. N., \& Risnawita, R. (2014). Teori - Teori Psikologi. Yogyakarta: Ar-Ruzz Media.

Handoko, T. H. (2014). Manajemen personalia \& Sumberdaya Manusia Edisi 2. Yogyakarta: BPFE-Yogyakarta.

Hartawati, D., \& Mariyati, S. (2014). Hubungan Antara Self-efficacy Dengan Burnout Pada Pengajar Taman KanakKanak Sekolah "X" Di Jakarta. Jurnal Psikologi 12 (2), 54-60. (Online), (http://journal.unair.ac.id/filerPDF/jppp2a9996ff38full.pdf), diakses 2 November 2017.

Kilapong, S. N. (2013). Kepemimpinan Transformasional, Self Efficacy, self Esteem Pengaruhnya Terhadap Kepuasan Kerja Karyawan PT. Tropica Cocoprima Manado. Jurnal EMBA, 1 (4), 141-150. (Online), (https://ejournal.unsrat.ac.id/index.php/emba/article/view/2645), diakses 2 November 2017.

Munandar, A. S. (2014). Psikologi Industri dan Organusasi. Jakarta: UI Press.

Rahman, U. (2013). Efikasi Diri, Kepuasan Kerja, Dan Organizational Citizenship Behavior Pada Guru MAN Di $\begin{array}{lllll}\text { Sulawesi. Lentera } & \text { Pendidikan. } & 16 & (1), & 115 .\end{array}$ (Online),(http://journal.uinalauddin.ac.id/index.php/lentera_pendidikan/article/view/493), diakses 2 November 2017.

Sardiman. (2014). Interaksi \& Motivasi Belajar Mengajar. Jakarta: PT. RajaGrafindo Persada.

Solichin, M. R. (2013). Pengaruh Kepuasan Kerja Dan Stres Kerja Terhadap Kinerja Guru Dalam Meningkatkan Mutu Akademik Lulusan Pada SMA RSBI Di Kabupaten Sidoarjo. Jurnal Ekonomi Pendidikan dan Kewirausahaan, 1(1). (Online), (https://journal.unesa.ac.id), diakses 10 November 2017.

Spector, P. E. (1997). Job Satisfaction Application,Assessment, Causes, and Consequences. California: Sage Publications.

Sugiyono. (2016). Metode Penelitian Pendidikan Pendekatan Kuantitatif,Kualitatif, dan R\&D. Bandung: Alfabeta.

Suharsono, Y., \& Istiqomah. (2014). Validitas Dan Reliabilitas Skala Self Efficacy. Jurnal IImiah Psikologi Terapan, 2 (1), 144-151. (Online) (http://ejournal.umm.ac.id/index.php/jipt/article/view/1776/1864), diakses 18 April 2018.

Sujarweni, W. (2014). Metodologi Penelitian Lengkap, Prkatiks, dan Mudah Dipahami. Yogyakarta: Pustakabarupress.

Sutanto, S. (2005). Menggunakan SPSS untuk Statistik Parametrik. Jakarta : Gramedia. 
Efektor, Volume 7 Issue 1, 2020, Pages 80 - 89

Nur Hasanah, Nadhirotul Laily

Tirtarahardja, U., \& Sulo, L. (2012). Pengantar Pendidikan. Jakarta: Rineka Cipta.

Waluyo, M. (2013). Psikologi Industri. Jakarta: Akademia.

Wijono, S. (2015). Psikologi Industri \& Organisasi Edisi Revisi. Jakarta: Prenadamedia Group. 